\title{
A Importância da Inclusão da Variável Ambiental na Gestão Portuária
}

\author{
Maria Cristina Fogliatti de Sinay (UNIGRANRIO) - cristinasinay@gmail.com \\ Sabrina Diogenes de Carvalho (Min. dos Transportes - Quebec-Canadá) - sabrinadiogenes@globo.com \\ Iluska Lobo Braga (UNIGRANRIO) - iluskalobo@gmail.com
}

\begin{abstract}
RESUMO:
Após repercussões mundiais dos impactos ambientais negativos causados pela instalação, operação e manutenção de grandes projetos, organismos internacionais financiadores passaram a recomendar aos países a inclusão de estudos da Avaliação de Impactos Ambientais nas suas solicitações de financiamento. No Brasil, instituiu-se o processo de licenciamento ambiental segundo o qual vários empreendimentos entre os quais os Portos são obrigados a desenvolver os mencionados estudos. Complementando esses, e como base para alcançar a sustentabilidade, vários empreendimentos estão adotando um sistema de gestão ambiental tendo como base três elementos fundamentais: (a) divisão do empreendimento em setores homogêneos, (b) descrição das atividades desenvolvidas em cada setor e (c) associação destas com impactos negativos passiveis de acontecer. Estes elementos permitem alinhavar um sistema de Gestão Ambiental o complementando com medidas mitigadoras, programas de qualidade e plano de contingência. O objetivo deste estudo, de natureza teórica e descritiva embasado em análise documental consiste em apresentar os elementos (a), (b), e (c) mencionados para o setor portuário brasileiro. O estudo permitiu concluir que a viabilização da gestão ambiental nos portos ainda é um desafio pela complexidade e importância do setor e pelo fato da variável ambiental ter sido incorporada tardiamente tornando o assunto delicado de se contornar.
\end{abstract}

PALAVRAS-CHAVE: Gestão Ambiental Portuária. Variável Ambiental na Gestão Portuária. Atividade Portuária e Impactos Ambientais Negativos.

\section{The Importance Of The Inclusion Of The Environmental Variable In Port Management}

\begin{abstract}
After the repercussions of the negative environmental impacts caused by the installation, operation and maintenance of projects, international funding agencies recommended the organizations to present studies related to Environmental Impact Assessment for their funding requests. The Brazilian environmental licensing process was established, obliging enterprises to present those studies to be in conditions to work. In addition to these, and as a basis for achieving sustainability, several enterprisers are adopting environmental management systems based on three fundamental elements: (a) division of the enterprise into homogeneous sectors, (b) description of the activities carried out in each sector, and (c) their association with negative passible impacts. These elements constitute a preliminary Environmental Management System to be completed with mitigating measures, quality programs and contingency plans. The purpose of this study, of a theoretical and descriptive nature based on documentary analysis, consists in presenting the elements (a), (b) and (c) before mentioned for the Brazilian port sector. This study allowed concluding that the feasibility of environmental management in the ports was, and still is, a challenge, due to the complexity and importance of the sector and to the fact that the environmental variable was later incorporated, making the subject more delicate to be treated.
\end{abstract}

KEYWORDS: Environmental Port Management. The Environmental Variable in Port Management. Port Activities and Negative Environmental Impacts.

\section{S. Universidade \\ Federal Fluminense}

R. Desembargador Ellis Hermydio Figueira, 783, Bloco A, sl. 218, Aterrado. 27213-415 - Volta Redonda, RJ - Brasil www.uff.br

Copyright (C) 2017 RASI. Todos os direitos, até mesmo de tradução, são reservados. É permitido citar parte de artigos sem autorização prévia, desde que seja identificada a fonte 


\section{A Importância da Inclusão da Variável Ambiental na Gestão Portuária}

\section{Introdução}

Até a década de 60 do século passado, o conhecimento e o desenvolvimento tecnológico/industrial estavam associados apenas com o crescimento econômico, não se preocupando com a conservação do meio ambiente. Os primeiros estudos sobre os impactos ambientais resultantes do processo de desenvolvimento humano surgiram na década de 60 nos países desenvolvidos, após a percepção da vulnerabilidade dos ecossistemas diante de alguns acidentes ocorridos, tal como a contaminação da costa do extremo sudoeste da Inglaterra pelo vazamento e naufrágio do petroleiro Torrey Canyon, em 1967 (Fogliatti, Fillipo, Goudard, \& 2004).

O grande aumento populacional ocorrido no século XX, aliado a um acelerado crescimento da indústria e da agricultura provocaram o aparecimento de problemas ambientais tais como a elevação da temperatura do planeta, a poluição dos recursos hídricos, a poluição atmosférica e a poluição sonora. Esta crescente degradação ambiental veio a ocasionar uma maior preocupação da sociedade e das autoridades, que passaram a considerar a capacidade de regeneração da natureza e dos recursos ambientais em frente às agressões provocadas pelo homem, como aspectos essenciais para a melhoria das condições de vida da população (Fogliatti, Campos, Ferro, Sinay, \& Cruz, 2011).

Após a Conferência das Nações Unidas sobre Meio Ambiente Humano, realizada em Estocolmo em 1972, organismos internacionais como o Banco Mundial e o Banco Interamericano do Desenvolvimento, em virtude das repercussões mundiais dos impactos ambientais negativos causados por grandes projetos por eles financiados, passaram a recomendar a inclusão de estudos de Avaliação de Impactos Ambientais nas solicitações de financiamentos.

No Brasil, somente na década de 80 , estudos sobre os impactos ambientais começaram a ser desenvolvidos pelos empreendimentos e solicitados pelos órgãos ambientais, em função da pressão da sociedade já conscientizada quanto aos benefícios advindos da preservação ambiental e das imposições dos bancos mundiais de investimento para a liberação de empréstimos (Fogliatti et al., 2004).

Desde 1981 e de acordo com a Lei Brasileira nº 6.938/81, o Licenciamento Ambiental tornou-se obrigatório em todo o território nacional condicionando o funcionamento de atividades efetiva ou potencialmente poluidoras. E pela Constituição de 1988, toda atividade com potencial poluidor deve apresentar um Estudo de Impacto Ambiental e respectivo Relatório de Impacto Ambiental como subsídio para o processo de licenciamento.

Os problemas de degradação ambiental e da perda de qualidade de vida agravam-se com a instalação e operação de grandes empreendimentos como é o caso dos portos (Maia, Moraes, Sinay, \& Cunha, 2010). Isto ocorre devido ao fato de que as atividades exercidas nestas instalações propiciam externalidades negativas no ambiente em que se inserem como a redução da fluidez no trânsito, o agravamento dos níveis de ruído, o aumento da poluição do ar e redução da qualidade da água.

Como integrantes dos sistemas de transportes, os terminais portuários são elementos chaves, caracterizados por serem pontos de entrada ou de saída de veículos e pessoas, onde o fluxo de transporte é iniciado, terminado ou transferido, antes, durante e depois do movimento das cargas ou passageiros. Neste contexto, os portos podem ser considerados como um dos tipos de empreendimentos que podem ocasionar maior variedade de impactos devido a serem 
instalações nas quais o exercício das atividades atrai um contingente significativo de viagens, reduzindo a qualidade de vida da sociedade.

De acordo com a Associação Nacional de Transporte Aquaviário, o Brasil tem uma faixa costeira de $8.698 \mathrm{~km}$ de extensão, $50.000 \mathrm{~km}$ de rios navegáveis e cerca de $98 \%$ de seu comércio exterior circula por meio de seus portos nacionais, movimentando recursos de aproximadamente U\$ 100 bilhões por ano. Estes números apontam a importância do planejamento e controle das atividades portuárias visando à redução da degradação ambiental da área de influência destas instalações (ANTAQ, 2007).

Ieda Novais, diretora corporativa da BDO, rede mundial em auditoria, tributos e advisory services, opina que os portos brasileiros, apesar de competitivos do ponto de vista comercial, não tem igual destaque quando o tema é Gestão Ambiental. Para o pesquisador de políticas sustentáveis e modais ecoeficientes, Washington Soares, são poucas as empresas que utilizam o sistema portuário nacional que se preocupam com as questões ambientais (Sustentabilidade, 2010). Segundo os pesquisadores Kitzman e Asmus (2006) e Porto e Teixeira (2002) isso foi motivado, talvez, pelo fato de que no processo de reformas do setor, iniciado na década de 1990, a dimensão ambiental não foi considerada estratégica.

Vários pesquisadores como Fogliatti et al. (2011) afirmam que uma das formas de evitar ou reduzir as externalidades negativas de qualquer que seja a organização é gerir a mesma levando em consideração impactos econômicos, sociais e ambientais, isto é, aplicando a gestão ambiental, entendida esta como "forma como uma organização administra as relações entre suas atividades e o meio ambiente que as abriga, observadas as expectativas das partes interessadas" (Viterbo Junior, 1998, p. 51); e como "conjunto de medidas e procedimentos bem definidos que, se adequadamente aplicados, permitem reduzir e controlar os impactos introduzidos por um empreendimento sobre o meio ambiente" (Valle, 2002, p. 69), ou como “(...) conjunto de programas e de práticas administrativas e operacionais voltadas à proteção do ambiente e a saúde e segurança de trabalhadores, usuários e comunidades" (Kitzman \& Asmus, 2006, p. 1042).

Essa gestão ambiental deve ser embasada no reconhecimento dos impactos negativos passiveis de serem gerados pelas atividades desenvolvidas no local. Fogliatti et al. (2011) apresentam três elementos iniciais como essenciais à dita gestão ambiental: (a) a divisão do empreendimento em setores homogêneos, ou seja, instalações onde atividades semelhantes são desenvolvidas, (b) apresentação destas atividades e (c) associação de cada uma das atividades relacionadas com os impactos negativos passíveis de serem gerados nos componentes ambientais presentes no local.

Este trabalho tem como objetivo apresentar esses três elementos da gestão ambiental para os portos brasileiros, úteis para o posterior desenvolvimento de um Sistema de Gestão Ambiental.

Para alcançar este objetivo este artigo, ensaio teórico de natureza descritiva está constituído por mais três sessões nas que se apresentam, respectivamente, as unidades portuárias, os três elementos básicos de um sistema de gestão ambiental e as conclusões finais.

\section{Terminais Portuários: Conceito e Classificação}

De acordo com Carvalho (2008) uma unidade portuária, em sua concepção mais geral, é qualquer instalação onde seja possível realizar o transbordo de mercadorias ou passageiros entre os meios aquático e terrestre sem distinção de tamanho ou forma jurídica de exploração. 
Quando esta unidade é constituída por um conjunto de instalações dedicadas, tecnicamente denominadas terminais, e outras não dedicadas, acrescidas de instalações de apoio, que estão sob gestão de uma entidade pública - Autoridade Portuária passa a ser denominada porto organizado, conforme estabelecido pela Lei 8.630/93.

Essa Autoridade Portuária é o gestor do porto organizado que tem como funções controlar a exploração dos portos pela iniciativa privada (presente nas instalações portuárias e terminais), fiscalizar operações, contratos e atividades, credenciar operadores, manter as condições de navegabilidade, realizar o planejamento estratégico e zelar para que os serviços se realizem com regularidade, segurança, eficiência e respeito ao meio ambiente (Lei 8630/1993).

De acordo com Porto e Teixeira (2002), as unidades portuárias podem ser de três tipos: convencionais, de trânsito e concentradoras, cada uma delas com funções, desempenhos e características específicas, conforme definidas a seguir.

Os portos convencionais são portos de pequeno ou médio porte, localizados fora de grandes eixos de deslocamentos de cargas internacionais e possuem infraestruturas básicas de atracação, armazenagem, faixa de circulação, equipamentos de movimentação vertical e horizontal de cargas e acessos rodoferroviários. Estes portos movimentam cargas múltiplas, secas e líquidas, havendo predominância de carga geral, com algum volume de carga fracionada, sendo também encontrada a carga granelizada, especialmente o trigo.

Os portos de trânsito são os que operam carga conteinerizada em grandes embarcações - full containers. Trata-se de plataformas logísticas que atuam em apoio a uma navegação intensiva, acumulando carga para futuro despacho. Por suas peculiaridades, são portos menos agressivos ao meio ambiente que os anteriormente mencionados em função do perfil das atividades que exercem.

Os portos concentradores são os que mais interferem no meio ambiente, pois operam uma grande variedade de cargas, em volumes muito superiores aos demais tipos, necessitando de amplas áreas para suas instalações, somados aos transtornos ocasionados pelas atividades industriais nele desenvolvido. Têm função de regular o fluxo de cargas, estocando-as por períodos de tempo para posterior distribuição, processam matérias-primas energéticas e industrializam outros produtos diversos.

\section{Elementos essenciais para pefinição de um sistema de gestão ambiental para portos}

A seguir, serão apresentados cada um dos elementos essenciais a um sistema de gestão ambiental para os portos brasileiros.

\subsection{Divisão dos portos em setores homogêneos e atividades desenvolvidas em cada um}

Os setores homogêneos que constituem um porto são quatro, quais sejam: o canal de acesso, o anteporto, o porto, com sua bacia de evolução, e o retroporto.

Na Figura 1 é apresentado, como exemplo destes setores, o arranjo geral do porto de Recife. 


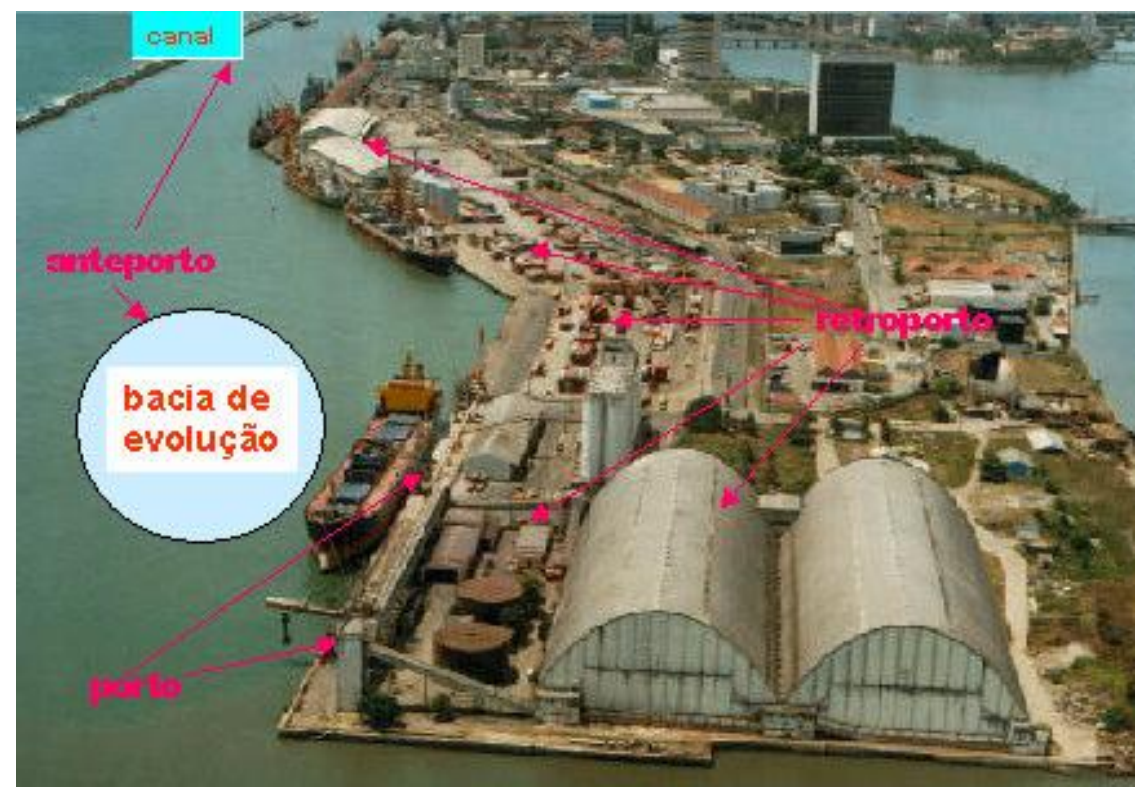

Figura 1. Arranjo Geral Porto de Recife.

Fonte: http://www.transportes.gov.br/bit/portos/recife/porecife.htm

O canal de acesso liga o alto mar às instalações internas do porto, permitindo a entrada e saída dos navios nas instalações portuárias.

O ante-porto é a área marítima onde os navios fundeiam, aguardando a visita das autoridades policiais, aduaneiras e da saúde, a fim de desembaraçar o navio.

O porto consiste da área onde se encontram o cais e as instalações de acostagem dos navios, em frente às quais se estende a bacia de evolução das embarcações. Essa última área serve às manobras dos navios na atracação e desatracação.

O retroporto é a área terrestre onde se situam os armazéns, as áreas de estocagem e as destinadas à consolidação e desconsolidação de cargas. Ainda conta com os edifícios de administração e serviços, as instalações das modalidades terrestres de acesso, como vias para transporte interior e os pátios ferroviários e rodoviários. Participam também do retroporto interfaces com os serviços externos, como a rede e subestações de energia elétrica, canalizações e caixas d'água potável, industrial e de incêndio, linhas físicas de telecomunicações, estação de tratamento de esgotos. Complementam o retroporto as portarias de entrada e controle, guaritas de segurança pessoal e patrimonial, áreas destinadas à administração compreendendo escritórios, locais para manutenção de equipamentos e navios, Terminais Retroportuários Alfandegados e Depósitos Alfandegados Públicos.

Os terminais marítimos intermodais são atendidos pelos modos de transporte rodoviário e ferroviário, podendo se agrupar de maneira a formar os terminais intermodais marítimo-rodoviários e marítimo-rodo-ferroviário. Para Pereira (2001), os principais componentes desses tipos de terminais são os subsistemas ferroviário, rodoviário, de transbordo e armazenagem e de apoio.

O subsistema ferroviário compreende as linhas ferroviárias incluindo as operações de recepção de carga, vistoria, expedição, formação e partida dos trens e manobras. Este subsistema é constituído por: acesso ferroviário, feixe de recepção, feixe de expedição, feixe de decomposição, classificação e formação, linhas de estacionamento e desvios, linhas de abastecimento, manutenção e reparos leves. 
O subsistema rodoviário é constituído pelas áreas de circulação e de espera, estacionamento, controle de saída e chegada de caminhões. Este subsistema é composto pelo portão de regresso/saída, acesso rodoviário, área de estacionamento e oficinas para manutenção rotineira e reparos leves em caminhões.

O subsistema de transbordo e armazenagem é constituído por instalações e infraestruturas necessárias para o transbordo de cargas de um modo de transporte para outro ou para as áreas de armazenagem dos contêineres, onde são realizadas as operações de desconsolidação e consolidação dos mesmos. Também participam deste subsistema o pátio de transbordo e os pátios de armazenagem das cargas, armazéns de consolidação/desconsolidação, oficinas de manutenção de equipamentos de movimentação, oficinas de reparos de contêineres e as vias para o transporte interno.

No subsistema de apoio, realizam-se os serviços de controle e gerência das operações e administração do terminal, possibilitando a integração do terminal com os diversos subsistemas e com o meio externo. Ele é constituído pela infra-estrutura de acessos, pelos edifícios de gerência comercial e por instalações complementares destinadas à instalação de leasing de contêineres, de empresas rodoviárias, seguradoras, balanças de medição, banco, entre outros.

Observa-se então que as atividades desenvolvidas nos diversos setores homogêneos, também conhecidas como características operacionais, são: a entrada e saída da carga do porto por via terrestre, o carregamento ou descarregamento dos navios com a utilização de equipamentos especializados assim como o empilhamento e desempilhamento das cargas, o transporte das cargas do cais ao armazém através das vias de transporte interior, a estocagem dessas, a retirada da carga no armazém e a transferência direta da carga dos navios para os caminhões ou vagões ferroviários através de correias transportadoras.

\subsection{Principais impactos negativos provocados pela atividade portuária}

As diversas atividades desenvolvidas e a sobreposição das áreas portuárias produzem efeitos cumulativos e sinérgicos que só poderão ser mitigados com ações coletivas e articuladas (Koelher \& Asmus, 2010).

A presença de carga manuseada nos portos traz uma diversidade de possíveis problemas ambientais, devido a esse efeito cumulativo das situações de risco que as atividades produzidas proporcionam ao meio ambiente.

Entre os principais componentes ambientais afetados pelas atividades portuárias, destacam-se o ar, a água, ruído e vibrações, odor, topografia, hidrologia/oceanologia, fauna e flora aquáticas e terrestres, paisagem, aspectos socioculturais e aspectos socioeconômicos.

De acordo com Porto e Teixeira (2002), ANTAQ (2007) e Carvalho (2008) dentre os diversos impactos ambientais negativos provocados pela interação entre as atividades portuárias e os componentes ambientais presentes no local, destacam-se:

- Modificações na dinâmica da zona costeira, presença de erosões, assoreamentos,

- Alterações na linha da costa,

- Modificações ou supressão da paisagem natural,

- Movimentação e disposição de material terroso por dragagem ou aterro,

- Alterações na biota,

- Supressão de manguezais e outros ecossistemas, 
- $\quad$ Contaminação da água e do ar, do solo, do subsolo e do lençol freático por perda ou fuga de carga poluente ou substância de outra origem, ou por lançamento de efluentes líquidos e gasosos,

- $\quad$ Absorção de grande faixa costeira para uso exclusivo portuário,

- $\quad$ Exclusão de outras atividades de subsistência e de lazer, como a pesca, e o turismo,

- Geração de resíduos sólidos provenientes das instalações do porto ou de indústrias vinculadas,

- Introdução de organismos estranhos ao meio ambiente portuário encontrados na água de lastro ou pelo transporte de cargas ou passageiros contaminados,

- Poluição e contaminação do solo e da água por lançamento de esgotos e outros dejetos,

- Interferência no conforto ambiental tal como perda da quietude, do isolamento e característica da paisagem.

Segundo a Tavares (2001), Rato (2002), ANTAQ (2007), e Carvalho (2008) os impactos oriundos das operações das embarcações ocorrem em maior número nas interfaces marítimas do porto. Destacam-se dentre eles:

- Poluição do ar, água e solo devido a vazamento, ruptura e transbordamento ou derramamentos de óleo durante a operação de abastecimento e transferência entre embarcações ou entre embarcação e terminal ou por colisão, encalhe e vazamentos de embarcações que resultam em derramamento da carga ou de combustível ou pelo uso de tintas tóxicas pelas embarcações,

- $\quad$ Poluição do ar causada por combustão e pela ventilação da carga, resultante das operações com carga seca como cimento, grãos, minério e carvão,

- Destruição de comunidades aquáticas provocada pelos efeitos do movimento da embarcação durante manobra, amarração e fundeio, e das pás dos hélices dos navios deslocando o material do fundo, principalmente se constituído de areia fina, lama ou site,

- Resíduos gerados pela embarcação,

- Lançamentos de esgotos sanitários em locais ou volumes inapropriados quando isto só é permitido a distâncias superiores a 12 milhas da costa,

- Transferência de organismos aquáticos nocivos e agentes patogênicos, por meio da água de lastro,

- Geração de lixo doméstico ou operacional e outros,

- Ocorrência de acidentes envolvendo matérias, equipamentos e recursos humanos.

Quanto à necessidade da instalação de um porto, de dragagens de berços e canais de acesso, derrocamentos, aterros, enrocamentos, infraestrutura de armazenagem, edificações em geral, acessos terrestres e outros, podem ser destacados, de acordo com Multiservice (1997), Companhia Docas (2002), Almeida (2004) e Carvalho (2008) os impactos a seguir:

- $\quad$ Alteração da linha de costa (morfologia),

- Supressão de vegetação,

- Alteração ou perda da camada superficial do solo,

- Modificação no regime dos corpos d água (regimes hidráulicos),

- $\quad$ Agressão a ecossistemas, 
- Aparecimento de outras vidas animais estranhas ao ambiente,

- Perda ou exclusão de outras atividades econômicas,

- $\quad$ Acidentes e doenças com operários e equipamentos,

- $\quad$ Agressão ao solo, ar, mar, rios, estuários e outros ambientes naturais.

Para IAPH (1991), Diaz (2002), Guedes (2005) e Carvalho (2008) na fase de operação, os terminais portuários podem ser fonte de impactos ambientais negativos pelo manuseio, transporte e armazenagem da carga, bem como pela manutenção da infra-estrutura, pelo abastecimento e reparo de máquinas, equipamentos e veículos em geral, que quando realizados de forma inadequada, podem gerar:

- Resíduos sólidos e líquidos,

- Lançamento de efluentes em corpos d'água,

- Poluição do ar, da água, do solo e do subsolo,

- Perturbações diversas por trânsito de veículos pesados,

- Ocorrência de acidentes, envolvendo materiais, equipamentos e operários,

- Doenças e perturbações para os operários,

- Alteração da paisagem.

Deve ser salientado que na legislação consultada se constata a observância de que a União ou a entidade concessionária do porto organizado é responsável pelo território dentro dos seus limites, isto é, em nenhum momento se prevê a conservação, preocupação ou responsabilidades com a parte externa ou entorno do porto (Carvalho, 2008).

A Lei ${ }^{\circ}$ 8.630/93, conhecida como Lei dos Portos, que dispõe sobre o regime jurídico da exploração dos portos organizados e das instalações portuárias estabelece que cabe à União explorar, diretamente ou mediante concessão, o porto organizado. Essa lei define que a área do porto organizado é a compreendida pelas instalações portuárias - ancoradouros, docas, cais, pontes e piers de atracação e acostagem, terrenos, armazéns, edificações e vias de circulação interna, bem como pela infra-estrutura de proteção e acesso aquaviário ao porto guias-correntes, quebra-mares, eclusas, canais, bacias de evolução e áreas de fundeio. Apenas estas áreas que devem ser mantidas pela Administração do Porto.

Porto e Teixeira (2002) ainda afirmam que uma das principais consequências da instalação e operação de unidades portuárias é advinda da atividade comercial e industrial realizada na área do entorno do porto. Assim sendo, essas consequências indesejadas também deveriam ser tratadas como responsabilidade da unidade portuária. Estes pesquisadores Porto e Teixeira (2002) apresentam o entorno como a área não portuária que gravita ao redor do porto (Figura 2). É todo o contorno sob influência das atividades exercidas no porto, incluindo o fornecimento de infra-estrutura residencial, de abastecimento e de circulação. Sua consideração amplia o estudo de impacto ambiental para todo e qualquer espaço físico vinculado à atividade portuária em questão, não apenas à área do porto organizado. 




Figura 2. Espaço portuário.

Fonte: Porto e Teixeira (2002).

A atividade comercial e industrial está constituída pelos processos que se desenvolvem nas superfícies da água ou do pavimento portuário, compreendendo o transporte marítimo de carga nas proximidades do porto e dentro dele, serviços de apoio à navegação, manuseio de carga a bordo e no cais, deslocamento de carga ao longo das instalações, armazenagem, conferência de volumes embarcados e desembarcados e todas as atividades de natureza industrial e comercial que acontecem no porto.

Assim, quanto às atividades instaladas na área do entorno do porto e de acordo com Carvalho (2008), os principais impactos negativos gerados diretamente pela operação são:

- O aumento da densidade demográfica da região,

- O esgotamento dos recursos energéticos,

- A sobrecarga nas infra-estruturas de apoio,

- Rede de esgotos, de abastecimento e de circulação,

- Alteração nos perfil sócio-econômico e cultural da população local,

- A importação de mão-de-obra,

- A poluição do ar e do solo,

- A poluição visual,

- Os transtornos no tráfego da região do entorno,

- A alteração dos níveis de serviço das vias,

- A diminuição da segurança de cargas, veículos e pessoas,

- $\quad$ aumento do número de acidentes envolvendo a população do entorno,

- $\quad$ O incremento de ruídos e vibrações,

- $\quad$ A modificação do uso, valor ou ocupação do solo, na perda de áreas verdes e de lazer.

\section{Conclusões}

Os portos brasileiros apresentam capacidade de atendimento aquém do necessário para atender a demanda portuária, provocando longas filas de cargas, custos elevados, baixa produtividade, perdas de mercadorias e outros impactos ambientais negativos. Assim sendo, investimentos no setor são necessários para tornar os portos competitivos no mercado internacional.

A importância da atividade portuária para a economia brasileira e a necessidade de aumentar a eficiência e produtividade destes empreendimentos são notórios, como também o é a necessidade de investimentos de certo pleito direcionados não apenas à melhoria da infra- 
estrutura portuária e ao aumento da capacidade de manuseio de produtos, mas também a implementação da Gestão Ambiental das atividades relacionadas para evitar o agravamento do quadro de deterioração das áreas vizinhas ao porto.

É algo fácil de entender que o poder público no seu papel de regulador e a iniciativa privada como concessionária e operadora, devam trabalhar juntos para sanar as atuais deficiências buscando a definição de estratégias comerciais, financeiras e de gestão implementando um efetivo sistema de gestão ambiental portuário, onde prevaleça a responsabilidade em relação ao meio ambiente, entendido este como os meios, físico, biótico e antrópico, sobre os interesses dos shareholders, isto é, sobre interesses puramente econômicos de lucro imediato.

As várias deficiências encontradas no setor portuário - altos custos, baixa produtividade, burocracia governamental, serviços não competitivos, tornaram necessário o processo de modernização dos portos, iniciado na década de 1990 com a Lei de Modernização dos Portos (Lei $\mathrm{n}^{\circ}$ 8.630/93), que estabeleceu o novo modelo brasileiro de exploração portuária (Koelher \& Asmus, 2010).

A viabilização da gestão ambiental nos portos foi, e ainda é, um desafio, pela complexidade e importância do setor e pelo fato da variável ambiental ter sido incorporada tardiamente. Ainda, a participação nestes empreendimentos portuários de diferentes órgãos públicos e privados com atribuições e exigências diversas, tornam o assunto ainda mais delicado de se contornar.

Para Kitzmann e Asmus (2006) se faz necessária uma mudança cultural que contemple a consideração da questão ambiental, acompanhada da regulação compartilhada e complementada com a adoção de tecnologia de suporte à tomada de decisão para mudar, positivamente, a realidade portuária brasileira, e para fazer frente, de forma digna os desafios impostos pelo crescimento significativo do comércio exterior que pressiona consideravelmente o sistema portuário brasileiro.

\section{REFERÊNCIAS}

Almeida, S. R. (2004). Subsídios para o gerenciamento ambiental de projetos de dragagem em portos. Rio de Janeiro : Instituto Militar de Engenharia. 190p.: il.

ANTAQ - Agência Nacional de Transportes Aquaviários (2007) Desempenho Portuário. Disponível em: http://www.antaq.gov.br/novositeAntaq/default.asp\#. Acesso em março de 2007.

ANTAQ - Agência Nacional de Transportes Aquaviários (2007) Situação dos portos quanto ao licenciamento. Disponível em: http://www.antaq.gov.br/novositeantaq/GestaoAmbiental/Relatorio.pdf. Acesso em março de 2007.

Companhia Docas do Rio de Janeiro. (2002) Projeto de Dragagem no Canal de Acesso e das Bacias de Evolução dos Terminais do Porto do Rio de Janeiro e de Niterói - Estudo de Impacto Ambiental. Rio de Janeiro, 2002. 309 p. il. 
Lei $n^{\circ}$ 8.630, de 25 de fevereiro de 1993. (1993) Dispõe sobre o regime jurídico da exploração dos portos organizados das instalações portuárias e dá outras providências. Diário Oficial da União. Brasília, Seção 1, página 235, fevereiro 1993.

Lei $n^{\circ}$ 6.938, de 31 de agosto 1981. (1981) Dispõe sobre a Política Nacional do Meio Ambiente, seus fins e mecanismos de formulação e aplicação, e dá outras providências. Diário Oficial da União. Brasília, 02 de setembro 1981.

Constituição da República Federativa do Brasil (1988) - Brasília, DF : Senado Federal.

Carvalho, S. D. (2008) Processo de Licenciamento Ambiental de Pólos Geradores de Viagens: O caso portuário. Dissertação (Mestrado em Engenharia de Transportes), Rio de Janeiro, Instituto Militar de Engenharia.

Diaz, M. N. (2002) Explotación portuaria. Consideraciones ambientales. Madrid: III Master en Ingeniería de Puertos y Costas.

Fogliatti, M. C., Campos, V. B. G., Ferro, M. A. C., Sinay, L., \& cruz, I. (2011) Sistema de Gestão Ambiental para empresas. 2. Ed. Rio de Janeiro: Interciência. 150 p. ISBN 978.85.7193.257.9

Fogliatti, M. C, Filippo, S., \& Goudard, B. (2004) Avaliação de Impactos Ambientais: Aplicação aos Sistemas de Transporte. Editora lnterciência: Rio de Janeiro.

Guedes, L. F.O. (2005). Subsídios para a implantação do sistema de gestão ambiental em portos organizados. Rio de Janeiro : Instituto Militar de Engenharia, 2005. 176 p.: il.

IAPH, The International Association of Ports and Harbors. (1991) Guidelines for Environmental Planning and Management in Ports and Costal Area Development.

Kitzman, D.; \& Asmus, M.. (2006) Gestão Ambiental Portuária: Desafios e Possibilidades. RAP-Revista de Administração Pública. Rio de Janeiro 40 (6): 1041-60, Nov./Dez.

Koelher, P. H. W.; \& Asmus, M. L. (2010) Gestão Ambiental Integrada em Portos Organizados: uma análise baseada no caso do porto de Rio Grande, RS-Brasil. Revista da Gestão Costeira Integrada. Journal of Integrated Coastal Zone Management 10 (2): 201-215

Maia, M. L. A.; Moraes, E. B. A. de; Sinay, M. C. F.; \& Cunha, R.F. de F. (2010) Licenciamento de Pólos Geradores de Viagens no Brasil. Transportes, v. 18, p. 17-26.

Multiservice engenharia ltda. (1997) Projeto de Dragagem do Canal de Acesso ao Porto de Sepetiba - Estudos de Impacto Ambiental. Companhia Docas do Rio de Janeiro. Rio de Janeiro. 130 p. il.

Pereira, G. (2001) Adequabilidade e Alocação de Equipamentos em Terminais Multimodais de Contêineres. Dissertação (Mestrado em Engenharia Transportes) Instituto Militar de Engenharia. Rio de Janeiro. 
Porto M., Teixeira S. (2002) Portos e Meio Ambiente. Aduaneiras.

Rato, J. L.D. (2002) Terminales de graneles sólidos. Madrid: III Master en Ingeniería de Puertos y Costas.

Tavares, M. L.S. (2001) Proposta de Aplicação do QFD à Gestão Ambiental de Terminais Portuários de Petróleo e Derivados. Dissertação de Mestrado em Engenharia de Produção. Rio de Janeiro: COPPE-UFRJ, novembro.

Sustentabilidade Portuária não se Resume apenas à Boa Política Ambiental. (2010) Revista Santos Modal. Edição 42. p. 22-24, ago/set.

Valle, C. E. (2002) Qualidade Ambiental: ISO 14000. 4ª Ed. revisada e ampliada, Editora SENAC. São Paulo.

Viterbo Junior, E. (1998) Sistema Integrado de Gestão Ambiental: Como implementar um sistema de gestão que atenda à Norma ISO 14000, a partir de um sistema baseado na norma ISO 9000, dentro de um ambiente de GQT. Editora Aquariana. São Paulo. 